\title{
Does Virtualization Capability Maturity Influence Information Systems Development Performance? Theorizing the Non-Linear Payoffs
}

\author{
Rohit Nishant \\ Université Laval \\ rohit.nishant@fsa.ulaval.ca
}

\author{
Shirish C. Srivastava \\ HEC Paris \\ srivastava@hec.fr
}

\author{
Bouchaib Bahli \\ Ryerson University \\ bahli@ryerson.ca
}

\begin{abstract}
Firms are increasingly relying on digital transformation and virtualization of physical IT assets to develop information systems projects. However, the assessment of this virtualization on the performance of information systems development (ISD) projects is still unclear. Drawing upon the theory of process virtualization, we develop and empirically test a research model describing the relationships of virtualization capability maturity (VCM) with ISD project performance. Our findings show inverted $U$ shaped relationships of VCM with both ISD process and product performance. Interestingly, ISD projects achieve performance improvements as they progress incrementally from VCM levels of 0 to 2, but at VCM level 3 performance declines. Also, we observe that at higher levels of VCM, ISD process performance declines more rapidly than ISD product performance and the resources spent on ISD project execution increases non-linearly with increasing levels of VCM. Our post-hoc analysis indicates that VCM and CMM exhibit a substitutive relationship for process performance. Implications for research and practice are discussed.
\end{abstract}

\section{Introduction}

Cloud computing and virtualization (fundamental technology behind a cloud) are emerging as the major digital transformation trends shaping the current day businesses [1]. The estimated cloud services market will be around $\$ 214.3$ billion in 2019 [2]. Virtualization, which implies the creation of a virtual version of a resource including computer hardware platforms, servers, desktops, operating systems, file, storage or network systems, is expected to enable organizations to reduce costs while ensuring better levels of service quality [3, 4], improve server utilization and enhancing their availability [5], reduce the time spent on routine IT administrative tasks, and enhance their IS configuration flexibility while ensuring better information security [6].
Despite, the growing interest of industry in virtualization and the metaphorical references to the expected benefits, theoretical understanding on the subject is still in a nascent stage. Notwithstanding the key role of virtualization in fostering digital transformation, empirical studies examining the performance benefits of virtualization are rather limited. Prior studies on virtualization and cloud computing have largely taken an operational perspective such as exploring the antecedents of virtualization, perceived benefits of virtualization, institutional influences on the use of virtualization tools, and issues involved in migrating to the cloud [7]. However, we need to understand the mechanisms through which the altered business value of virtualization can be realized. This study aims to help to fill this gap in the current research on virtualization. Hence, it will be interesting to examine the modalities through which virtualization influences organizational performance and to understand if any conditions can limit the possible benefits from such technologies. Motivated by this gap, in this research, we examine if the level of virtualization in an organization influences its information systems development (ISD) performance.

As with the adoption of many IT assets, organizations do not adopt virtualization technologies in a single step. Instead, they adopt different components of this technology rather gradually [8]. In the beginning, they virtualize a few specific resources and gradually adopt more comprehensive virtualization. Thus, at any given point in time, organizations will be at different levels of virtualization maturity [9] and the level of their virtualization capability maturity (VCM) can influence the performance of their specific organizational processes. In this research, we focus on one such organizational process - namely, information systems development (ISD), because ISD process in an organization is largely dependent on the management of information resources [10], which is closely linked to the virtualization tools and technologies [11]. Thus, VCM could influence the performance of ISD projects 
comprising two distinct but interrelated dimensions of ISD process and product performance. However, virtualization being a disruptive force could present challenges for the existing processes [12], thereby impacting ISD process performance differently from ISD product performance. Against this background, we examine the following research question:

RQ: Does virtualization capability maturity (VCM) have an influence on ISD project performance specifically ISD process and product performance?

Grounding the discussion in the theory of process virtualization, and building on the concepts from the business value of IT literature, we develop a model describing the relationships of virtualization capability maturity (VCM) with ISD project performance consisting of two dimensions - ISD process performance and ISD product performance. Next, we develop theoretical arguments describing the interaction of process-centric maturity with virtualization maturity in an organization and its consequent influence on ISD performance. This study has three key contributions. First, to the best of our knowledge, this study is one of the first to investigate the influence of VCM on ISD performance. Examining this relationship is crucial to understanding if the key to positive payoffs from virtualization tools and technologies such as cloud computing is the maturity of virtualization (VCM). Second, we demonstrate that VCM has different impacts on ISD process and product performance, specifically - ISD process performance declines more rapidly than product performance, demonstrating a more nuanced and complex relationship of VCM with performance than past research has envisaged. Finally, in our posthoc analysis, we show that conventional process standards (such as CMM) tailored for material IT assets need to be adapted to be able to deliver expected results for dematerialized IT in terms of VCM. Tradition physical IT assets in a datacenter can be tracked, maintained, and managed in conventional ways. Virtual assets pose challenges to organizations to control and manage them since they are more often provided in different cloud environments. This further contributes to the IS literature by suggesting a shift in the way future ISD processes need to be orchestrated in a virtualized environment.

\section{Theoretical Foundations and Hypotheses Development}

With the growing emphasis on software development towards the end of last century, a standard to measure the software development process maturity of an organization called the capability maturity model (CMM) was developed [13] [14]. CMM focuses on process improvements to deliver quality software and offers guidelines to help organizations improve their capabilities [15]. It also recognizes the salience of costs and productivity in software development processes [16]. According to the CMM model, as organizations define and standardize processes, they progress through five improvement levels from complete lack of maturity and disciplined processes (level 1) to highly mature and disciplined processes (level 5). Akin to CMM, studies $[17,18]$ have proposed the four-stage virtualization capability maturity (VCM) model (Figure 1).

Each stage is associated with the level of capacity and maturity of processes surrounding virtualization of IT assets. As assets are consolidated and resources are allocated through virtualization, operations are expected to become more efficient. In the first stage (level 0), the organization has no virtualization, only physical IT assets, and often dedicated data and server resources. At the level 1 level of maturity, organizations begin to share applications and minimize resource redundancy. Thus, processes could move from physical IT assets to shared applications. As organizations mature further in their virtualization, they substitute physical IT assets with virtual assets in a cloud environment such as Azure, Amazon AWS, and start leveraging the assets to realize the economy of scale (levels 2 and 3). Because a major proportion of IT infrastructure is virtualized, processes will advance from their focus on several individual IT assets (hardware and software) to a more integrative approach focused on shared resources and applications that can be easily accessible through a specific network.

The virtualization story began with the advent of the current century, and soon it was realized that in an "increasingly virtual society, more and more processes that have traditionally been conducted via physical mechanisms are being conducted virtually" $[19,20]$. Virtualization is increasingly transforming processes in several diverse contexts such as online shopping (e.g., Amazon), social networking sites (e.g., Facebook), and virtual worlds [3, 19]. Virtualization is a new wave of technology that disrupting the conventional IT by dematerializing physical IT assets. Given its propensity to create new products, services and transform the existing industry structure and dynamics, it fits the definition of 'disruptive innovation' [21]. Despite several potential benefits and capabilities to transform organizations, disruptive innovations also presents several challenges, specifically related to their implementation and management [22].

Several emergent challenges in managing increasing levels of virtualization could slow down the pace of benefits realized from higher levels of virtualization - resulting in a non-linear relationship 
between the level of VCM and ISD project performance. Figure 2 shows the research model. As a theoretical foundation, we draw arguments from the process virtualization theory (PVT) developed by [19].

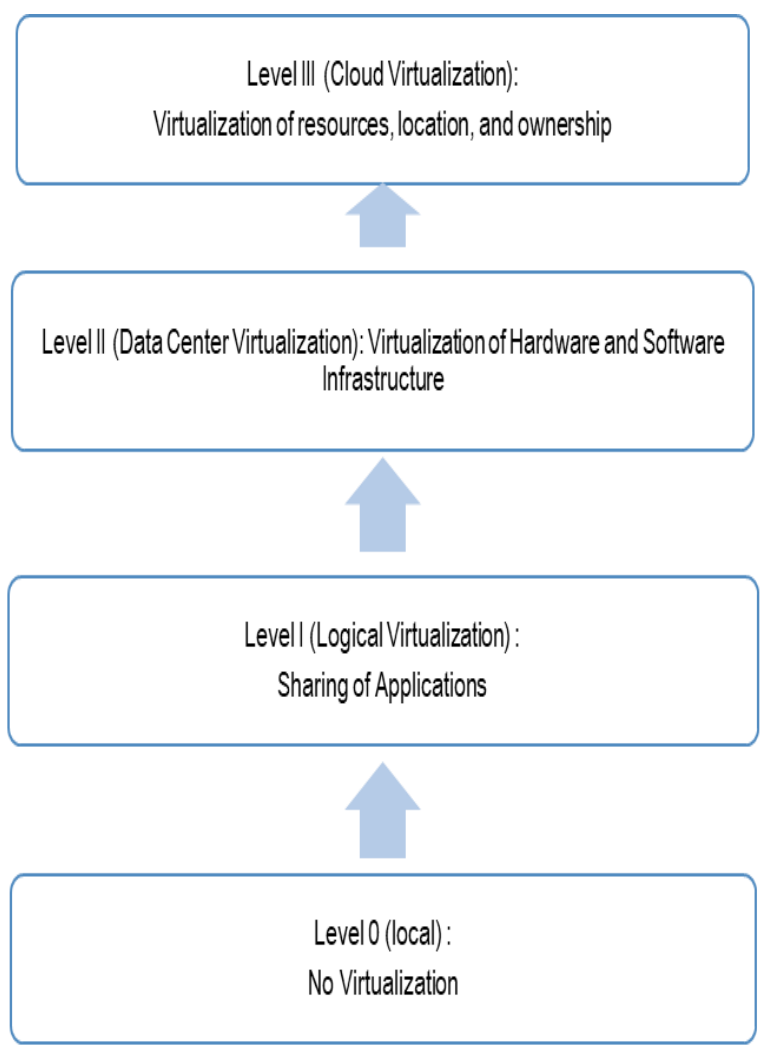

Figure 1. Virtualization Capability Maturity (VCM) Model
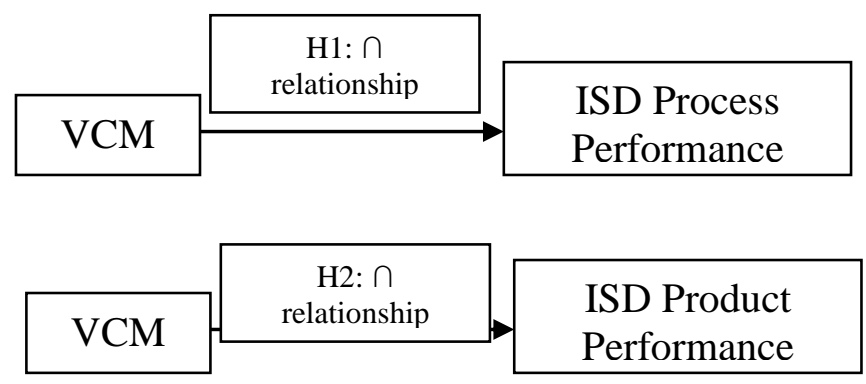

H3: Relationship between ISD Process Performance $>$ Relationship between ISD Product Performance

Figure 2. Research Model

Studies in innovation literature highlight the use of substantially different technologies that can result in innovative and new benefits for customers [23]. As discussed earlier, virtualization, which dematerializes IT is a substantially different technological artifact as compared to traditional physical IT assets. This shift offers several new benefits to customers such as flexibility in IT design and use. Nevertheless, the benefits for organizations that adopt a disruptive innovation are contingent on several non-technical organizational factors that need to be addressed [24]. PVT also examines whether a physical process can be conducted virtually in an effective manner. PVT suggests that there are factors that could inhibit a process capacity to be virtualized and consequently diminish performance benefits from virtualization [19]. These nuances about virtualization need to be specifically factored into the performance models associated with virtualization technologies.

The expected payoffs from new IT assets in an organization may often be hampered because ISD often involves greater costs and time than initially anticipated. These time and cost overruns contribute to the low success rate for ISD projects in other contexts such as online user communities, which on an average is about $55 \%$ [25]. In sum, organizations could experience performance improvement with virtualization. However, emergent changes in organizations and teams, skill gaps, learning requirements, and identification, and security concern could constrain them from realizing the promised benefits of virtualization.

ISD project performance comprises two distinct dimensions [26] - process performance and product performance. Process performance reflects the quality of the software development process [27]. In particular, process performance indicates whether during the ISD process, there was sufficient transfer of relevant knowledge and if the right controls were in place to ensure smooth execution of the project. Process performance in an ISD project is thus primarily related to learning the process and implementing the required control systems.

In conventional IT set-up, developers use a wide array of software and hardware technologies while working on a project. Managing projects within specified parameters, gathering requirements, conforming to users' expectations, and coordinating among developers and users is complex and difficult [26]. Consequently, shared knowledge grows slowly. In contrast, as virtualization increases, organizations replace diverse IT assets with an imitation of the single software, which reduces complexity and facilitates better coordination. In a scenario of increased homogeneity, organizations build comprehensive knowledge around processes or technologies rather than developing discrete pieces of knowledge around a wide array of processes and technologies, thereby 
improving the learning [28]. Also, developers can easily comply with specified parameters and can focus on understanding user requirements. Organizations can use virtualization to provide cloud services that give developers on-demand access to computing resources. On-demand access to computing resources can help developers improve their process productivity [5]. Thus, increase in virtualization maturity could improve process performance. However, there are also a few factors that could inhibit the benefits realized from virtualization.

Organizations with high level of VCM would experience discontinuity in the learning associated with conventional IT. Organizations would be in early stages of learning specifically procedural knowledge to manage virtualization. Consequently, tacit knowledge that often improves process performance would not have been completely acquired [29]. Organizations would also struggle to formalize team structures around overlapping virtual assets. Accordingly, processes that depend on the efficacy of teams would experience a decline in their performance.

Further, when an organization achieves a high level of virtualization maturity, concerns about identification and control of the virtualized assets would be extremely high. Organizations would divert focus from IS delivery to ensuring the proper identification and control mechanisms of virtualized IT assets, this may also inhibit their learning process. As organizations become more inward-focused and less customerfocused, process performance could decline, specifically in terms of meeting customers' requirements. Moreover, an excessive focus on identification and control could weaken the organization's focus on meeting the cost and time constraints. In sum, organizations with lower VCM levels would benefit from better coordination as some IT assets would be virtualized resulting in increasing homogeneity. However, organizations with higher levels of VCM would experience disruption in learning and departure from focus on process control. Thus, process performance would initially increase with virtualization maturity but will decline at higher levels of VCM. Following these arguments, we hypothesize:

H1: Information systems development (ISD) process performance will exhibit an inverted U shaped relationship with virtualization capability maturity (VCM), such that ISD process performance is positively related to VCM until a certain point. Beyond this maxima, ISD process performance will exhibit a negative relationship with VCM.

Organizations often develop inertia and fail to respond adequately to disruptive innovations, which also extends to managing these innovations [30].
Organizations are often comfortable with the legacy routines and team members are behaviorally embedded in traditional legacy processes [31]. When the organization is comprehensively virtualized as in the case of high level of VCM, legacy routines would also be disrupted. Organizations would be having legacy processes for delivering IS to their customers. In a scenario of virtualization, such processes would be disrupted and new procedures would have to be developed. The existing knowledge base of organizations, especially tacit knowledge, would be around managing physical IT assets. But such knowledge base may prove to ineffective for a virtualized set-up.

Though organizations would benefit at lower levels of virtualization maturity in terms of on-demand flexible IT use but as organizations venture towards a deeper use of virtual IS resources, they may need to divert their focus from technical performance to other aspects such as management of control and identification of virtualized IT assets. To set up new processes for ensuring access to credible employees. Moreover, the existing processes and procedures could come in the way of new procedures sometimes leading to a duplication of procedures. This would again lead to inefficiencies. Specifically, responsiveness and capability to adapt to changing business needs could diminish due to increased focus on managing the new virtual systems rather than on the business needs. Thus, we expect that ISD product performance would initially increase with virtualization capability maturity (VCM) but could decline at higher levels of VCM. Consequently:

H2: Information systems development (ISD) product performance will exhibit an inverted U-shaped relationship with virtualization capability maturity (VCM), such that ISD product performance is positively related to VCM until a certain point. Beyond this maxima, ISD product performance will exhibit a negative relationship with VCM.

Although we argue for the inverted U-shaped relationship between process and product performance with virtualization maturity, it is not clear if the relationship of VCM with process performance will differ from VCM's relationship with product performance. Specifically, whether the process and product performance follow similar trajectories in their relationship with virtualization maturity.

As organizations virtualize more, significant changes would be required in processes. Specifically, process dimensions such as learning would undergo rapid transformation. 
Organization-acquired knowledge regarding technical and procedural knowledge could be less applicable to virtualized environment, as it developed and evolved in a conventional physical IT environment. Legacy development processes were also designed for the conventional IT environment. Consequently, legacy development processes need to be redesigned to adapt to the dematerialized nature of virtualized organizational set-up. Organizations due to the changes required in development processes could experience new constraints in terms of meeting specified quality parameters. Organizations would be required to devote more resources to adapt processes to virtualized setup rather than for interaction with customers. Thus, we expect ISD process performance to decline sharply with high virtualization maturity.

As hypothesized, virtualization maturity would also influence product performance. Given the transformation in processes and emerging challenges from such changes, organizations would become more inward focused and reduce their emphasis on customer interactions. This could adversely impact responsiveness and flexibility. Nevertheless, organizations would still strive to meet the expectation of customers. Despite inward focus, organizations would interact, albeit relatively less, with customers to understand their expectations and design IS to respond to the dynamic business environment and evolving needs. Consequently, the impact of virtualization on product performance would be less relative as compared to process performance. Hence, we hypothesize:

H3: The relationship between virtualization capability maturity (VCM) and ISD process performance is significantly stronger relative to the relationship between VCM and ISD product performance such that ISD process performance declines more sharply at higher levels of virtualization maturity.

\section{Method}

\subsection{Data Collection and Measures}

To test the proposed hypotheses, we employed a survey research methodology. To identify the survey respondents, we used an official database of CMM appraisals comprising about 500 organizations. Invitations for the online survey were sent to senior IS managers who could answer questions about their organization's recent ISD projects. We closely followed Dillman's recommendations [32] for developing and administering the web surveys. We received 107 responses and after accounting for missing values we used 90 responses for our analysis where the data was complete on all the variables of our research interest -- virtualization maturity, ISD process performance, ISD product performance and a host of control variables such as organization size, team size, industry etc.

For measuring, virtualization capability maturity (VCM), we adapted measures from [17]. Based on the highest rating received from the respondents for different VCM levels, the VCM of the organization was determined. For measuring ISD process and product performance, we adapted Nidumolu's [33] ISD performance measure which was again measured on a scale of 1-7. Non-response bias was assessed using ttests between early and late respondents (within the first 3 weeks and after the 3-week period) and also between the participating and non-participating firms based on a number of variables such as assets, number of employees, annual sales and industry sector. No significant differences were found. Furthermore, we examined the extent of common method bias using Harman's one-factor test [31] and found no significant method bias confounding our results.

Although our items were adapted from past research where psychometric properties have already been established, we tested for statistical validity, factor loadings, and reliability. Items with low loadings on the corresponding factor and high cross-loadings were dropped. Consequently, five ISD process performance items and five ISD project performance items were retained for the final empirical analysis. The measures exhibit sufficient convergent and discriminant validity.

\subsection{Econometric Models}

We use several models and distinct sub-models to test the two distinct relationships in this study. First, we test the relationships between the levels of virtualization maturity with ISD process and product performance. Second, we test the relationships between the different levels of virtualization maturity with ISD process and product performance. Our econometric specifications for testing these relationships are:

\section{Non-Linear Specification (Quadratic Model)}

Process Performance $=\alpha+\beta 1(\mathrm{VCM})+\beta 2$ $\left(\mathrm{VCM}^{2}\right)+\beta 3($ Organization size $)+\beta 4($ team size $)+\beta 5$ (Sector dummy) $+\varepsilon \ldots$ (I) 
Product Performance $=\alpha+\beta 1(\mathrm{VCM})+\beta 2$ $\left(\mathrm{VCM}^{2}\right)+\beta 3($ Organization size $)+\beta 4$ (team size $)+\beta 5$ (Sector dummy) $+\varepsilon \ldots$ (II)

Specification to test relationships of specific level with performance

Process Performance $=\alpha+\beta 1($ level0) $+\beta 2($ level1 $)$ $+\beta 3($ level2 $)+\beta 4$ (level3) $+\beta 5($ Organization size $)+$ $\beta 6($ team size $)+\beta 7$ (Sector dummy) $+\varepsilon$

Product Performance $=\alpha+\beta 1($ level0) $+\beta 2($ level1 $)$ $+\beta 3($ level2 $)+\beta 4$ (level3) $+\beta 5($ Organization size $)+$ $\beta 6$ (team size) $i+\beta 7$ (Sector dummy) $+\varepsilon$.

Our models I - IV test the relationships of virtualization maturity (in terms of absolute level as well as different levels of virtualization capability maturity) with ISD product and process performance. In our econometric models (I - II), we also include a quadratic term to test the hypothesized inverted Ushaped relationships. Following the recommended analytical procedures, we centered VCM variable before creating the nonlinear (quadratic term) to control for multicollinearity. In our econometric specification, we also control for organization size, team size, and industry sector as these could influence ISD performance [33]. The industry sector was controlled using dummies for different sectors.

Also, as discussed earlier, ISD process and product performance are two distinct dimensions of project performance and might be related to each other. This might bias estimates computed using conventional OLS regression. Hence, we use seemingly unrelated regression (SUR) to test our hypotheses. SUR addresses potential concerns about correlated error terms in a regression model that consists of several regression equations [10]. In our econometric specification, error terms in equations for $\mathrm{H} 1$ and $\mathrm{H} 2$ could be correlated, as our DVs might be correlated to each other. This again justifies our use of SUR.

While $\mathrm{H} 1$ and $\mathrm{H} 2$ focused on the relationships of process and product performance with virtualization maturity, H3 specifically focused on the distinction between the two relationships. Hence, we compare the slopes of these relationships at specific points.

\section{Results}

Table 1 shows the estimates for our analysis for H1-H3.

\begin{tabular}{lllll}
\multicolumn{2}{l}{ Table 1.Results } \\
\hline Variables Model & Model & Model & Model \\
\hline
\end{tabular}

\begin{tabular}{|c|c|c|c|c|}
\hline & I & II & III & IV \\
\hline & $\begin{array}{c}\text { Process } \\
\text { Perform } \\
\text { ance }\end{array}$ & $\begin{array}{l}\text { Product } \\
\text { Performa } \\
\text { nce }\end{array}$ & $\begin{array}{c}\text { Process } \\
\text { Performa } \\
\text { nce }\end{array}$ & $\begin{array}{c}\text { Product } \\
\text { Performa } \\
\text { nce }\end{array}$ \\
\hline (Absolute & $0.25^{*}$ & $0.24 *$ & & \\
\hline $\mathrm{VCM}$ & $\{0.142\}$ & $\{0.125\}$ & & \\
\hline Level) & & & & \\
\hline (Absolute & -0.587 *** & $-0.357 * *$ & & \\
\hline VCM & $\{0.138\}$ & $\{0.122\}$ & & \\
\hline Level) $^{2}$ & & & & \\
\hline VCM Level & & & -0.076 & $-0.097 *$ \\
\hline 0 & & & $\{0.057\}$ & $\{0.064\}$ \\
\hline VCM Level & & & $0.666 * *$ & $0.578 * *$ \\
\hline 1 & & & $\{0.104\}$ & $\{0.103\}$ \\
\hline VCM Level & & & $0.220 * *$ & 0.129 \\
\hline 2 & & & $\{0.099\}$ & $\{0.098\}$ \\
\hline VCM Level & & & 0.051 & -0.05 \\
\hline 3 & & & $\{0.104\}$ & $\{0.102\}$ \\
\hline Team Size & $-0.214 *$ & $\begin{array}{l}-0.163 \\
\{0.112\}\end{array}$ & $-0.355^{* *}$ & $-0.26^{*}$ \\
\hline Organizatio & $0.172^{* *}$ & & $0.194 * *$ & $0.161^{* *}$ \\
\hline n Size & $\{0.051\}$ & $\{0.045\}$ & $\{0.033\}$ & $\{0.031\}$ \\
\hline Industry & Yes & Yes & Yes & Yes \\
\hline dummy & & & & \\
\hline
\end{tabular}

Note: Standard error are in parentheses, ${ }^{*}(p<0.05),{ }^{* *}(p<0.01)$ (onetailed), virtualization maturity was operationalized in two ways. First, organization was considered to be at level of maturity for which it received highest rating. For instance, if an organization received 6,6.2, 6.5, and 6.8 for level $0,1,2$, and 3 , it was considered to be at level 3 . Model 3 and Model 4 take into account the ratings for different level of maturity. We applied stringent data cleaning criteria. If we include dropped data into our empirical analysis, the findings are similar.

Our empirical analysis presents several interesting insights. In our quadratic models I and II, the estimate for the quadratic term of VCM level is significant. The estimates for both process performance $(\beta=-0.587, p$ $<0.05)$ and product performance $(\beta=-0.357, \mathrm{p}<0.05)$ are significant. Moreover, estimates for linear term $(\beta$ $=0.25, \mathrm{p}<0.05 ; \beta=0.24, \mathrm{p}<0.05)$ are also significant. We also plotted the relationships to better understand them. The graphs depict inverted U-shaped relationships of VCM level with ISD process performance and product performance. Both product and process performance increase with increasing levels of virtualization and subsequently decline. Thus, both $\mathrm{H} 1$ and $\mathrm{H} 2$ are supported.

Estimates from models III and IV suggest that level 0 is not significantly related to ISD process performance but negatively related to ISD product performance. But, levels I and II are positively related to both process and product performance. However, estimates for level III are not significant, perhaps explaining the underlying mechanism for the inverted 
U-shaped relationships observed in Model I. For product performance, the estimates for level II as well as level III are not significant. This suggests that there is no significant change in product performance as organizations progress from level I to level II. This perhaps contributes to the relatively flat nature of the plot for the relationship between product performance and VCM level.

Among control variables, most of the industry dummies are significant implying the significant impact of the industry sector on how virtualization influences ISD performance. The estimates for team size were negative, but the estimates for organization size were positive. This suggests that plausibly issues such as coordination emerge with the increase in team size. But large organization size reflects large employee and resource pool to the manage projects. Perhaps, this is the reason for the positive relationship between organization size and performance.

We compare slopes of relationships of ISD process and product performance with VCM to test H3. The plot suggests that process performance increases as well as declines more sharply than product performance. However, when we compare linear and quadratic slopes of different relationships, we find that linear slopes are not significantly different from each other. But, quadratic slopes are significantly different from each other ( $\mathrm{t}$-value for the difference of slope = $1.7, \mathrm{p}<.05$, one-tailed). Thus, H3 is partially supported.

\subsection{Post Hoc Analysis}

With increasing virtualization maturity, more processes would require significant changes. Disruptive technology requires organizations to adapt their processes [34]. Existing processes need to be redesigned as well as some of the activities need to be abandoned [35]. Many firms already use conventional IS capability maturity models such as CMM, which focuses on standardizing processes to realize benefits from physical IT and processes. CMM being a conventional standard is aimed at strengthening processes meant for conventional, physical IT assets. Hence a higher CMM level would indicate higher embeddedness of legacy processes in the organization. Thus, to contribute to this debate, we posit that, in its actual format, high CMM levels would negate process performance benefits from high virtualization maturity. High CMM level and subsequently formalized processes would also adversely impact organizations' ability to flexibly use virtualized IT assets to develop responsive IS for their clients. Consequently, high CMM level would also negate product performance benefits from high virtualization maturity. Hence, it is plausible that in the ISD context, CMM and VCM share non-complementary or substitutive relationship. Since 1991 CMM has morphed in different versions and updates, we emphasize that virtualization of software development requires CMM adaptations of its processes, their management and optimization. While VCM incorporates such adaptations, CMM in itself does not.

To further deepen our understanding and insight of the study's findings, we examined the interplay between CMM level and VCM level and their subsequent impact on project performance. Since CMM level influences optimization of organizational processes in general, it could have a spillover effect on the payoffs from VCM. Against this backdrop, we tested model $\mathrm{V}$ and VI that investigates the joint effect of CMM and VCM by computing the estimate for the interaction of VCM with CMM (Table 2).

We tested an alternative linear model that included linear term of CMM, VCM, and their interaction term. We centered the variables before computing the interaction term to reduce multi-collinearity. Our econometric specification is:

$$
\begin{aligned}
& \text { Process Performance }=\alpha+\beta 1(\mathrm{VCM})+\beta 2 \\
& (\mathrm{CMM})+\beta 2(\mathrm{VCM} * \mathrm{CMM})+\beta 4 \\
& (\text { Organization size })+\beta 5(\text { team size })+\beta 6 \\
& \text { (Sector dummy) }+\varepsilon \ldots \ldots \ldots . .(\mathrm{V}) \\
& \text { Product Performance }=\alpha+\beta 1(\mathrm{VCM})+\beta 2 \\
& (\mathrm{CMM})+\beta 2(\mathrm{VCM} * \mathrm{CMM})+\beta 4 \\
& \text { (Organization size) }+\beta 5(\text { team size })+\beta 6 \\
& \text { (Sector dummy) }+\varepsilon \ldots . . . . . .(\mathrm{VI})
\end{aligned}
$$

\begin{tabular}{|c|c|c|}
\hline Variables & Model V & Model VI \\
\hline (Absolute VCM Level) & $\begin{array}{c}\text { Process } \\
\text { Performance } \\
1.971 * * \\
\{0.669\}\end{array}$ & $\begin{array}{c}\text { Product } \\
\text { Performance } \\
0.94^{*} \\
\{0.554\}\end{array}$ \\
\hline (CMM Level) & $\begin{array}{l}1.233 * * \\
\{0.239\}\end{array}$ & $\begin{array}{l}0.91 * * \\
\{0.197\}\end{array}$ \\
\hline VCM*CMM & $\begin{array}{c}-0.388^{* * *} \\
\{0.150\}\end{array}$ & $\begin{array}{c}-0.168 \\
\{0.124\}\end{array}$ \\
\hline Team Size & $\begin{array}{c}-0.338 * * \\
\{0.137\}\end{array}$ & $\begin{array}{c}-0.338 * * \\
\{0.114\}\end{array}$ \\
\hline Organization Size & $\begin{array}{c}0.033 \\
\{0.055\}\end{array}$ & $\begin{array}{c}0.031 \\
\{0.046\}\end{array}$ \\
\hline
\end{tabular}

The estimates for the interaction terms were negative and significant for ISD process, but nonsignificant for product performance (Process performance: $\mathrm{Beta}=-.389, \mathrm{p}<0.01$, Product Performance: Beta $=-.168, \mathrm{p}>0.05)$.

Table 2.Results for Model V and VI 
Industry dummy

Yes

Yes

Note: Standard error are in parentheses, $*(\mathrm{p}<0.05), * *$ $(\mathrm{p}<0.01)$

\section{Discussion and Conclusion}

Our study indicated that virtualization capability maturity (VCM) level is not linearly related to ISD process and product performance. Instead, we find an inverted U-shaped relationship. The relationship exhibits significant non-linearity attributable to the initial strong performance increase followed by subsequent decline.

Our other empirical models provide the underlying rationale that explains the observed inverted U-shaped relationship. Both ISD process performance and product performance initially increase with increased VCM and subsequently decline. As aforementioned, virtualized IT assets such as data centers allow organizations to better allocate their resources and reduce resource redundancy. Decline in resource redundancy could resolve issues related to coordination, responsiveness, and resource optimization, which would result in improved process and product performance. However, when there is a substantial increase in the level of virtualization, organizations would need to undergo significant transformation. Organizations in conventional IT setup would have to re-engineer numerous processes to conform to the new virtualized environment. Specifically, organizations would have to dedicate resources to design mechanisms to address emergent concerns about security, identification, and control. Organizations would also have to invest in reskilling their employees and developing a new organizational structure to adapt to the virtualized environment. Consequently, payoffs from such major changes may not be initially visible. In fact they might show a decline as seen in the current research. Hence, without directed process interventions, organizations beyond level 2 may not realize the anticipated returns from virtualization. This also explains the non-significant relationship of VCM with performance at level 3 of VCM. Thus to benefit from virtualization, organizations need to invest in change management directed at aligning their processes and procedures to the emergent virtualized IT.

From the results, we also see that process performance shows a sharper decline as compared to product performance, perhaps because significant changes are required in processes that have high levels of virtualization. Positive payoffs from major process changes would be realized after significant time has elapsed from the initial implementation. However, linear slopes were not significantly different from each other.

CMM and VCM are substitutes for process performance, However, the estimate for CMM is positive. This suggests that organizations cannot realize maximum improvement in process performance from virtualization when both VCM and CMM are at high levels. In fact, organizations with high CMM level realize marginal process performance benefits from progression to high levels of virtualization. This result reiterates the fact that $\mathrm{CMM}$ and $\mathrm{VCM}$ are fundamentally different in their focus. But we also see that CMM and VCM are not substitutes for product performance. They are positively related to product performance. Thus, product performance will improve with increase in CMM and VCM levels. A plausible explanation is that both CMM and VCM are primarily organization centric with improving organizational process, whereas product performance is often driven by aspects such as interaction with clients. Organizations irrespective of any internal transformation try to maintain their level of client engagement. Thus, any conflict between CMM and VCM would have marginal effect on product performance.

While prior research has shown a linear relationship between a traditional CMM maturity level and IS development projects [36] such an assertion cannot be concluded about the relationships of VCM level with process and product performance. Although virtualization lowers IT costs and helps in better resource management, it does require organizations to manage several change management issues related to people and process. This deduction is further alluded to by our post-hoc analysis which shows positive relationships of VCM levels with and time, cost, and effort spent on ISD projects.

This study offers several implications for further research. First, the study invokes arguments grounded in process virtualization theory to argue that there are several organizational factors that could possibly negate or rather limit the positive payoffs from virtualization. The findings demonstrate that IT with transformative potential such as virtualization does not yield the expected benefits due to several challenges. These challenges may not be related to technology per se but may primarily be organizational in nature. Our research thus contributes to the existing debate on the realization of the business value of IT. IS literature has had a long tradition of deliberation on the business value of IT [37].

Second, the study theorizes and empirically tests the relationships of VCM level with ISD process and product performance. We observe inverted U-shaped 
relationships, indicating that many technological resources can have non-linear business values constrained by certain boundary conditions. These boundary conditions can be different for different contexts and need to be sufficiently explored and examined for extending the theory on the business value of disruptive IT.

However, our study is limited by a small sample size and thus is primarily exploratory in nature. Future research need to examine the impact of virtualization for a larger sample. Future research might also investigate the relationship between virtualization and ISD project performance in specific sectors. Future research can also investigate the underlying mechanisms determining the observed inverted Ushaped relationship. Our research is the one of the first small steps in this direction but there is a need to examine it more deeply from managerial and organizational context as highlighted in recent literature reviews [38].

Our study also indicates that VCM and CMM are not complements, instead they are substitutes for ISD process performance. CMM has been in existence before VCM and organizations have often invested time, effort and capital for achieving high levels of CMM . Future research needs to explore mechanisms to realize maximum benefits from both VCM and CMM. Alternatively, future research could also investigate how organizations with high CMM levels successfully transition to high VCM levels.

Practitioners should recognize that higher levels of virtualization do not yield immediate benefits Organizations must first focus on their business and production processes before benefits from virtualization can be realized. Major process and design changes might cause change management issues that organizations must plan to address. Practitioners must also realize that virtualization payoffs are often contingent on the specific context. Hence, there is a need to focus on the challenges associated with specific sectors and organizations to better align the virtualization efforts with the particular contextual nuances.

\section{References}

[1] Gartner Tech Trend. "Top 10 strategic technology trends for 2016: The device mesh", Gartner, 2016. Retrieved from https://www.gartner.com/doc/3229717.

[2] Gartner. "Gartner Forecasts Worldwide Public Cloud Revenue to Grow 17.5 Percent in 2019”, Gartner, 2019. Retrieved from https://www.gartner.com/en/newsroom/pressreleases/2019-04-02-gartner-forecasts-worldwide-publiccloud-revenue-to-g.
[3] R. Bose, X. Luo. "Integrative framework for assessing firms' potential to undertake Green IT initiatives via virtualization-A theoretical perspective." The Journal of Strategic Information Systems, 20(1), 2011, pp.38-54.

[4]M. Snellgrove. "Virtualization to business: Virtual infostructure," Cap Gemini, 2010. Retrieved from https://www.capgemini.com/resource-fileaccess/resource/pdf/Virtualization_to_Business__Virtual_Inf ostructure.pdf.

[5] E, Kotsovinos. "Virtualization: blessing or curse?." Communications of the ACM, 54,1, 2011, pp. 61-65.

[6] R. King. "Coca-Cola looks to secure edge for age of cloud, mobility. WSJ. Retrieved from http://blogs.wsj.com/cio/2015/03/23/coca-cola-looks-tosecure-network-edge-for-age-of-cloud-mobility/

[7] M.C. Messerschmidt, O. Hinz. Explaining the adoption of grid computing: An integrated institutional theory and organizational capability approach." The Journal of Strategic Information Systems, 22, 2, 2013, pp. 137-156.

[8] CIOReview. "IMSCAD is the world's leading specialist in graphics virtualization", 2016 Retrieved from http://virtualization.cioreview.com/cxoinsight/imscad-is-theworld-s-leading-specialist-in-graphics-virtualization-nid18458-cid-8

[9] D. Weiss, J. Repschlaeger, R. Zarnekow, H. Schroedl. "Towards a consumer cloud computing maturity model proposition of development guidelines, maturity domains and maturity levels." PACIS Proceedings, 2013, Paper 211. http://aisel.aisnet.org/pacis2013/211.

[10] S. C. Srivastava, T.S.H. Teo. "Contract performance in offshore systems development: role of control mechanisms." Journal of Management Information Systems, 29, 1, 2012, pp. 115-158.

[11] D. Zissis, D. Lekkas. "Addressing cloud computing security issues." Future Generation Computer Systems, 28, 3, 2012, pp. 583-592.

[12] A. Benlian, M. Koufaris, T. Hess. "Service quality in Software-as-a-Service: Developing the saas-qual measure and examining its role in usage continuance." Journal of Management Information Systems. 28, 3, 2011. pp. 85-126.

[13] J. Herbsleb, D. Zubrow, D. Goldenson, W. Hayes, M. Paulk. "Software quality and the capability maturity model." Communications of the ACM, 40,6, 1997, pp. 30-40.

[14] S .Akhlaghpour, L. Lapointe. "From Placebo to Panacea: Studying the Diffusion of IT Management Techniques with Ambiguous Efficiencies: The Case of Capability Maturity Model." Journal of the Association for Information Systems, 19,6, 2018, 4. 
[15] C.Amulen, G.M. Kituyi, E.Kabaale. "Critical parameters for the adoption of software capability maturity model by small and medium enterprises." International Journal of Agile Systems and Management. 9, 1, 2016, pp. 1-20.

[16] S.M. Krishnan, H.C. Kriebel, S. Kekre, T. Mukhopadhyay. "An empirical analysis of productivity and quality in software products." Management Science, 46, 6, 2000, pp. 745-759.

[17] K. Francis, P. Richardson. "Green maturity model for virtualization." MSDN Architecture Center, 2009. Retrieved from http://msdn.microsoft.com/enus/library/dd393310.aspx

[18] J. Staten, G. Schreck. "Assess your infrastructure virtualization maturity", 2009. Retrieved from http://www.fstech.co.uk/fst/whitepapers/Assess\%20yourself $\% 20-\% 20$ Virtualisation.pdf.

[19] E. Overby. "Process virtualization theory and the impact of information technology." Organization Science, 19, 2, 2008, pp. 277-291.

[20] E. Overby. Migrating processes from physical to virtual environments: Process virtualization theory. In Information Systems Theory, Springer, New York, 2012.

[21] CM. Christensen, ME. Raynor, R. McDonald. "What is disruptive innovation," Harvard Business Review, 93, 12, 2015, pp. 44-53.

[22] A.Ali, D.Warren , L. Mathiassen. "Cloud-based business services innovation: A risk management model," International Journal of Information Management. 37, 6, 2017, pp. 639-49.

[23] B.A. Sorescu, K. Chandy, C. Prabhu. "Sources and financial consequences of radical innovation: Insights from pharmaceuticals." Journal of Marketing, 67, 4, 2003, pp. 82102.

[24] F. S. Slater, J. Mohr, S. Sengupta. "Radical product innovation capability: Literature review, synthesis, and illustrative research propositions." Journal of Product Innovation Management, 31,3, 2014, pp. 552-566.

[25] Q.J. Dong, W. Wu. "Business value of social media technologies: Evidence from online user innovation communities." The Journal of Strategic Information Systems, 24, 2, 2015, pp. 113-127.

[26] K. Dongus, S. Ebert, M. Schermann, H. Krcmar. "What Determines Information Systems Project Performance? A Narrative Review and Meta-Analysis.” In System Sciences (HICSS), 2015 48th Hawaii International Conference on, IEEE, pp. 4483-4492).

[27] H. Barki, S. Rivard, J. Talbot. "An integrative contingency model of software project risk management."
Journal of Management Information Systems, 17, 4, 2001, pp. 37-69.

[28] J. Jiang, G. Klein, G. Hwang, J. Huang, Y. Hung. "An exploration of the relationship between software development process maturity and project performance." Information and Management, 41,3, 2004, pp. 279-288.

[29] C.López-Nicolás, AL. Meroño-Cerdán. "Strategic knowledge management, innovation and performance," International journal of information management, 31, 6, 2011, pp.502- 509.

[30] W. Hill, T. Rothaermel. "The performance of incumbent firms in the face of radical technological innovation." Academy of Management Review, 28,2, 2003, pp. 257-274.

[31] A. Malhotra, A. Majchrzak, R. Carman, V. Lott. "Radical innovation without collocation: A case study at Boeing-Rocketdyne." MIS Quarterly, 25, 2, 2001, pp. 229249.

[32] A. Dillman. Mail and internet surveys: The tailored design method, New York, Wiley, 2000.

[33] A. Nidumolu. "A comparison of the structural contingency and risk-based perspectives on coordination in software development projects." Journal of Management Information Systems, 13, 2, 1996, pp. 77-113.

[34] J. Birkinshaw, I.Visnjic, S.Best. "Responding to a potentially disruptive technology: How big pharma embraced biotechnology," California Management Review, 60, 4. 2018, pp. 74-100.

[35] R.C. Coombs. "When planned IS/IT project benefits are not realized: a study of inhibitors and facilitators to benefits realization." International Journal of Project Management, 33, 2, 2015, pp. 363-379.

[36] M. Unterkalmsteiner, T. Gorschek, A. Islam, C. Cheng, R. Permadi, R. Feldt. "Evaluation and measurement of software process improvement: A systematic literature review." IEEE Transactions on Software Engineering, 38,2, 2012, pp. 398-482.

[37] J. Dedrick. V. Gurbaxani, L. Kraemer. "Information technology and economic performance: A critical review of the empirical evidence." ACM Computing Surveys, 35,1, 2003, pp.1-28.

[38] M. Bayramusta, V.A.Nasir. "A fad or future of IT?: A comprehensive literature review on the cloud computing research," International Journal of Information Management, 36, 4, pp. 635-644. 